\title{
Editorial
}

\section{ACESSO ABERTO: DESAFIOS}

A discussão a respeito da importância de acesso aos produtos e processos de pesquisa para promover o conhecimento científico tem sido objeto de reflexão há muito tempo na literatura. No âmbito da Sociologia da Ciência, por exemplo, Robert Merton (1910-2003) em meados do século XX ressaltou que a produção científica é realizada de forma colaborativa e deveria ser destinada à comunidade científica, sendo o direito de propriedade do cientista reduzido ao seu reconhecimento por meio de citações (MERTON, 2013). Ainda que a visão de ciência de Merton, seja limitada ao contexto da época, apresentando uma versão objetiva e empirista da ciência, desvinculada de um contexto social mais amplo (BOURDIEU, 2004), tem o mérito de ressaltar que o reconhecimento científico ocorre por conhecimento e citação dos trabalhos publicados pelos pesquisadores e que o crescimento científico deve estar vinculado ao livre acesso do que é produzido pela ciência.

$\mathrm{Na}$ atualidade, as reflexões a respeito do livre acesso à produção científica se intensificam ainda mais pressionadas pelo acesso à internet e a velocidade em que as informações são disponibilizadas, consolidando um movimento para o alcance de informações, em contraposição ao modelo que restringe a comunicação científica (SUBER, 2012; ANDRADE; MURIEL-TORRADO, 2017). Nesse movimento, tem-se a expectativa de ver o conhecimento gerado, principalmente, por pesquisas financiadas com recursos públicos, liberados do controle de sua difusão e uso. Com efeito, nessa perspectiva, passariam as regras e as práticas a serem determinadas, antes de tudo, pelos investigadores, em nome do bem público.

$\mathrm{O}$ acesso aberto é um movimento internacional que visa conceder alcance online gratuito às publicações acadêmicas, sem barreiras financeiras e legais (SUBER, 2012). Desse modo, busca-se uma difusão das comunicações livre, respeitando os acordos legais de atribuição de autoria e de uso não comercial do material acessado.

Uma das iniciativas pioneiras para o acesso aberto é atribuída ao estadunidense Michael Stern Hart (1947-2011), fundador do Projeto Gutenberg, em 1971, o qual disponibiliza livros eletrônicos de forma gratuita na internet (COUTINHO; PESTANA, 2015; NEWBY, s/d). A expansão do alcance de iniciativas como a realizada pelo projeto 
DOI: https://doi.org/10.33238/ReBECEM.2021.v.5.n.2.28002

Gutenberg e a popularização crescente da internet contribuiu para o interesse ao acesso aberto de obras.

Na consolidação do movimento de acesso aberto, segundo Andrade e MurielTorrado (2017, p. 2), foram importantes as declarações "conhecidas por 3 Bs ou BBB: Budapeste, Bethesda e Berlim”, escritas de 2001 a 2003 e que propiciaram reflexões a respeito do acesso aberto em diferentes áreas do conhecimento, defendendo o acesso livre para compartilhar e utilizar os materiais disponíveis.

Para Suber (2012), uma das grandes barreiras que o acesso aberto busca romper é o estabelecimento de preços para ler um texto. $\mathrm{O}$ autor explicita que o custo estabelecido para ler um texto de modo individual pode até ser transponível, mas quando esse texto se soma a outros em um processo de revisão bibliográfica para elaboração de um projeto ou quando uma biblioteca precisa dar acesso a milhares de alunos e professores esse custo fica, muitas vezes, inviável, prejudicando a pesquisa. Nesse sentido, compreendemos que o aumento contínuo do volume de textos e o preço das assinaturas colocam, muitas vezes, as bibliotecas em situação difícil, já que, em geral, seus orçamentos não aumentam na mesma proporção, tendo de reduzir significativamente suas assinaturas.

O tema do acesso aberto é complexo e se confronta com diferentes barreiras, estabelecidas, principalmente, pelo resultado da economia do sistema de publicação, dominado por grandes editoras comerciais, que o tornou um negócio muito lucrativo. Nesse contexto, Barros (2012) indica a ocorrência de um movimento denominado de "primavera acadêmica" que vem questionar as editoras comerciais acadêmicas que visam objetivos de lucro. Entretanto, ainda que se tenha uma quantidade crescente de revistas com acesso aberto, muitos pesquisadores, devido ao sistema de avaliação de periódicos, atribuem o sucesso de suas publicações baseado, em grande parte, na influência das grandes editoras e no fator de impacto de revistas consideradas tradicionais (BARROS, 2012; FURNIVAL; SILVA-JEREZ, 2017). Barros (2012, p.366) destaca:

\footnotetext{
Um empecilho para a consolidação em larga escala do movimento de acesso livre na academia é que grande parte dos periódicos de acesso aberto, em diferentes campos do conhecimento, têm fatores de impacto muito abaixo dos títulos estabelecidos. Então, até que a comunicação científica encontre uma maneira melhor de avaliar o desempenho das pesquisas, é provável que a maioria dos acadêmicos continue a publicar em periódicos com maior fator de impacto.
}

Inferimos que isso acaba por explicitar uma certa cultura acadêmica que, muitas vezes, valoriza determinas publicações tanto para a submissão de artigos como para busca de textos para suas pesquisas. Barros (2012) reflete que grande número de periódicos com 
DOI: https://doi.org/10.33238/ReBECEM.2021.v.5.n.2.28002

alto fator de impacto está associado às revistas com fins lucrativos. Ou seja, na busca de ter uma publicação em uma revista com alto fator de impacto, pesquisadores acabam publicando em revistas com acessos restritos. Isso gera um mecanismo que se autossustenta, no qual se concentra uma suposta qualidade em um número pequeno de periódicos, com alto fator de impacto.

Outro ponto complexo é a cobrança dos custos de produção, editoração e processamento de artigos para os autores. Isso ocorre desde revistas com acesso restrito aos leitores até em revistas que sinalizam para o acesso aberto de seus textos e, que algumas vezes, apresentam taxas de publicações que superam milhares de euros (QUINTANILHA; TRISHCHENKO, 2021). Ainda que o trabalho de processamento de textos seja árduo, esses custos podem ser cobertos por instituições sem fins lucrativos, pelos próprios autores com taxas condizentes a esses gastos ou depender de trabalho de editores e equipes técnicas voluntárias.

O Programa de Pós-Graduação em Educação em Ciência e Educação Matemática da Universidade Estadual do Oeste do Paraná (PPGECEM/Unioeste) estabeleceu o acesso livre ao seu periódico, revisado por pares e sem cobrança de taxas de processamento dos artigos. Assim, a Revista Brasileira de Educação em Ciência e Educação Matemática (ReBECEM), desde o ano de 2017, tem acesso aberto aos seus textos por considerar essa a opção mais apropriada para assegurar a liberdade dos leitores e dos investigadores. $\mathrm{O}$ acesso livre à ReBECEM só é possível graças ao trabalho voluntário de pesquisadores vinculados ao PPGECEM/Unioeste, de uma rede espontânea de revisores e pela utilização de espaço em portal gerenciado pelo Projeto SABER (Sistema de Acesso à Biblioteca Eletrônica de Revistas) disponibilizado pela Unioeste.

A ReBECEM se utiliza de um sistema de gerenciamento de código livre gratuito o Open Journal Systems (OJS 2.4.8.5), com suporte e distribuição do Public Knowledge Project e licença GNU General Public License, como indicado no site da revista ${ }^{1}$. De acordo, com o Guia do usuário do OJS 3 (BRITO et al., 2018, p. 20), o Brasil é o "país com o maior uso do OJS no mundo, com mais de mil e setecentas revistas usuárias da ferramenta, revelando a importância deste software para o país na publicação de periódicos". OJS e suas atualizações são ferramentas extremamente importantes para o gerenciamento e processamento de periódicos, pois:

${ }^{1}$ http://e-revista.unioeste.br/index.php/rebecem/about/aboutThisPublishingSystem. 
DOI: https://doi.org/10.33238/ReBECEM.2021.v.5.n.2.28002

O Open Journal Systems (OJS) é uma aplicação web para a gestão completa do processo editorial de publicações periódicas, ou seja, da submissão dos artigos à publicação do fascículo. Faz a gestão de atividades dos atores envolvidos no processo, do fluxo editorial completo dos periódicos, desde a criação da revista até a manutenção dos números já publicados. Inclui a submissão do trabalho por parte dos autores, o registro das recomendações dos pareceristas em relação a este documento e sua aprovação ou rejeição pelo editor científico ou, também, pelo editor executivo; a publicação na web das informações sobre a publicação, seu histórico, e as edições e artigos em texto completo. Suporta também a publicação de recursos hipermídia. Oferece, ainda, ferramentas para pesquisa em seu conteúdo e a integração com outros sistemas para compartilhamento, divulgação, preservação e democratização do acesso ao conteúdo publicado. Possui plugins pré-instalados para atribuição automática de Digital Object Identifier (DOI) e indexação em diversos indexadores, que já estão integrados (BRITO et al., 2018, p. 20).

Somando-se a isso, em direção ao acesso livre, mas preservando os direitos de autoria e reconhecimento, a ReBECEM adota como sistema de licenciamento de conteúdo o Creative Commons - Atribuição-Não Comercial 4.0 Internacional. Essa licença indica que o material pode ser compartilhado e adaptado desde que se dê o crédito apropriado ao mesmo e que não seja usado para fins comerciais ${ }^{2}$

Os esforços da equipe da ReBECEM unem-se aos de pequenos grupos e periódicos de acesso aberto que estão fazendo campanha em vários níveis para promover novos cenários e modelos de publicação. Essas ações, embora ainda marginais, devem ser incentivadas e apoiadas em parcerias com organizações públicas ou privadas, sem fins lucrativos. Também, os pesquisadores devem assumir um papel a cumprir, no questionamento de práticas que cerceiam o acesso ao conhecimento.

Destacamos, que a disposição desse modelo aberto e sem custos, só é possível pela dedicação da equipe técnica e de editores bem como o trabalhado voluntariado de pareceristas, o que possibilita a realização de um trabalho sério, permitindo a difusão de artigos de qualidade para a área de Educação em Ciências e Educação Matemática.

\section{Referências}

ANDRADE, R. de M.; MURIEL-TORRADO, E. Declarações de acesso aberto e a lei de direitos autorais brasileira. RECIIS - Revista Eletrônica de Comunicação, Informação e Inovação em Saúde, Rio de Janeiro, v. 11, p. 1-5, nov. 2017. Suplemento. Disponível em: https://www.arca.fiocruz.br/handle/icict/23722. Acesso em 2 de agosto de 2021.

BARROS, M. A. A Primavera Acadêmica e o custo do conhecimento. Liinc Em Revista, Rio de Janeiro, v. 8, n. 2, p. 365-377, set. 2012. (Novos paradigmas da comunicação científica:

\footnotetext{
${ }^{2}$ https://creativecommons.org/licenses/by-nc/4.0/.
} 


\section{$\eta_{\text {eBECEM }}$}

Revista Brasileira de Educação em

Ciências e Educação Matemática

ISSN 2594-9179

DOI: https://doi.org/10.33238/ReBECEM.2021.v.5.n.2.28002

ampliando o debate). Disponível em: http://revista.ibict.br/liinc/article/view/3366/2967. Acesso em: 5 de agosto de 2021.

BOURDIEU, P. Para uma sociologia da ciência. Lisboa: Edições 70, 2004.

BRITO, R. F.; SHINTAKU, M.; CURADO, A. M. C. S. F.; ABADAN, D.; MACEDO, D. J.; SERRADAS, A.; SANTOS, P. R.; SOARES, S. B. C. Guia do usuário do OJS 3. Brasília: Ibict, 2018.144 p. Disponível em: https://bibliotecadigital.mdh.gov.br/jspui/handle/192/252. Acesso em 05 de agosto de 2021.

COUTINHO, P.; PESTANA, O. eBOOKS: evolução, características e novas problemáticas para o mercado editorial. PÁGINAS a\&b, s. 3, n. 3, p. 169-195, 2015. Disponível em:

http://aleph20.letras.up.pt/index.php/paginasaeb/article/view/672. Acesso em: 04 de agosto de 2021.

FURNIVAL, A. C. M.; SILVA-JEREZ, N. S. Percepções de pesquisadores brasileiros sobre o acesso aberto à literatura científica. Inf. \& Soc.:Est., João Pessoa, v. 27, n. 2, p. 153-166, maio/ago. 2017. Disponível em:

https://periodicos.ufpb.br/ojs2/index.php/ies/article/view/32667. Acesso em 2 de agosto de 2021.

MERTON, R. Ensaios de sociologia da ciência. São Paulo: Associação Filosófica Scientiae Studia/Editora 34, 2013.

NEWBY, G. B. Obituary for Michael Stern Hart. Project Gutenberg. Disponível em: <https://www.gutenberg.org/attic/hart.html\#obituary-for-michael-stern-hart>. Acesso em: 5 de agosto de 2021.

QUINTANILHA, T. L.; TRISHCHENKO, N. Acesso aberto e conhecimento científico: entre a res publica e o modelo de negócio. Uma Revisão da literatura. Comunicação e Sociedade, v. 39, p. 203-222, 2021. Disponível em:

https://revistacomsoc.pt/index.php/revistacomsoc/article/view/2756. Acesso em 5 de agosto de 2021.

SUBER, P. Open access. Cambridge: MIT Press, 2012. Disponível em: http://nrs.harvard.edu/urn-3:HUL.InstRepos:10752204. Acesso em 2 de agosto de 2021.

Cascavel, 19 de agosto de 2021.

Prof. Dr. Dartel Ferrari Lima

Profa. Dra. Fernanda Aparecida Meglhioratti

Profa. Dra. Rosana Franzen Leite

Editores da ReBECEM 